\title{
Pemanfaatan Teknologi $Q R$ Code Dalam Pengembangan Sistem Pendaftaran Calon Mahasiwa Baru di Universitas Islam Riau
}

\author{
Hendra Gunawan, ST, M.Eng \\ Jurusan Teknik Informatika, Fakultas Teknik, Universitas Islam Riau \\ Jalan Kaharudin Nasution Nomor 113, Pekanbaru \\ e-mail: hendra@eng.uir.ac.id
}

\begin{abstract}
Abstrak
Penerimaan mahasiswa baru (PMB) merupakan proses administrasi yang terjadi disetiap perguruan tinggi. Proses pendaftaran calon mahasiswa di Universitas Islam Riau dilakukan dengan cara pengisian kertas formulir oleh calon mahasiswa, kemudian data tersebut diinputkan kembali oleh panitia menggunakan komputer secara offline. Kesalahan penginputan ulang data calon mahasiswa oleh panitia $P M B$ sering terjadi. Oleh karena itu, dibangun sistem yang memanfaatkan teknologi QR Code yang diharapkan mengurangi resiko terjadinya kesalahan entri data.

Metode penelitian yang digunakan dalam penelitian ini adalah pengembangan sistem informasi penerimaan mahasiswa baru berbasis web dengan memanfaatkan teknologi QR Code. Pada QR Code yang dicetak oleh calon mahasiswa melalui sistem penerimaan mahasiswa baru berisi data mahasiswa sementara untuk di scan oleh operator panitia PMB agar data dapat masuk dalam database PMB secara offline. Dengan cara ini, maka operator panitia PMB tidak memasukkan secara manual melalui sistem dan lebih efisiensi dalam mengurangi spam pada form pendaftaran online.
\end{abstract}

Kata Kunci : Sistem Pendaftaran Online, Sistem PMB, Teknologi QR Code

\section{PENDAHULUAN}

Universitas Islam Riau atau disingkat dengan nama UIR merupakan salah satu perguruan tinggi yang concern terhadap pengembangan teknologi dan ilmu pengetahuan juga berupaya sebaik mungkin untuk dapat juga memanfaatkan teknologi informasi sebagai salah satu penunjang terciptanya sebuah sistematika kegiatan kampus baik itu administrasi maupun akademik yang efisien dan compatible dengan perkembangan zaman. Salah satu aktifitas perguruan tinggi yang memanfaatkan teknologi informasi ialah Seleksi Penerimaan Mahasiswa Baru (SPMB) yang diadakan setiap tahun oleh Universitas. Rerata jumlah pendaftar mahasiswa baru setiap tahunnya pada Universitas Islam Riau sekitar 5000 hingga 8000 orang per tahun.

Pada sistem pendaftaran dan proses seleksi penerimaan mahasiswa baru sebelumnya, calon mahasiswa yang datang diharuskan mengisi kertas form secara manual kemudian panitia PMB akan memasukkan data di komputer secara offline. Hal ini dapat menyebabkan kesalahan pengisian data oleh panitia, karena kesalahan membaca tulisan tangan calon mahasiswa maupun kesalahan input data diri calon mahasiswa oleh panitia. Banyaknya kertas formulir yang harus disediakan panitia pada setiap pelaksanaan PMB juga menyebabkan ketidakefisienan dan pemborosan pada penggunaan kertas.

Dibuatnya sistem informasi pendaftaran calon mahasiswa baru dengan memanfaatkan teknologi $Q R$ Code secara online bertujuan agar dapat membantu panitia dalam menyelesaikan permasalahan pada penginputan data calon mahasiswa baru. Hal ini pertama akan mengurangi terjadinya kemungkinan kesalahan pengisian data karena human error oleh panitia PMB dikarenakan oleh banyaknya data yang harus diinputkan oleh panitia PMB. Yang kedua adalah antisipasi spam data pada pendaftaran, karena input data sebenarnya hanya melalui scan $Q R$ Code oleh panitia PMB.

Dengan melihat permasalahan diatas dan adanya potensi untuk meneliti hal ini, maka penulis mengangkat penelitian ini dengan judul "Pemanfaatan Teknologi QR Code Dalam Pengembangan Sistem Pendaftaran Calon Mahasiwa Baru Di Universitas Islam Riau". 


\section{METODOLOGI PENELITIAN}

\section{Alat dan Bahan}

Pada penelitian ini dibutuhkan beberapa perangkat keras maupun perangkat lunak untuk tercapainya penelitian ini, diantaranya :

1. Alat Scan $Q R$ Code menggunakan smartphone Samsung Ace Android.

2. Software $Q R$ Droid untuk Smartphone Android, dapat diinstal melalui Play Store Android.

3. Personal Computer, Intel Core i3, RAM 2 GB.

4. XAMPP 1.7.3 sebagai virtual server PHP dan MySQL.

5. Library Generator $Q R$ Code yang dapat di download pada :

http://phpqrcode.sourceforge.net/

\section{Penggunaan QR Code pada sistem}

$Q R$ Code adalah suatu jenis kode matriks atau kode batang dua dimensi yang dikembangkan oleh Denso Wave, sebuah divisi Denso Corporation yang merupakan sebuah Perusahaan Jepang dan dipublikasikan pada tahun 1994 dengan fungsionalitas utama yaitu dapat dengan mudah dibaca oleh pemindai. QR merupakan singkatan dari quick response atau respon cepat, yang sesuai dengan tujuannya adalah untuk menyampaikan informasi dengan cepat dan mendapatkan respons yang cepat pula. Berbeda dengan Barcode, yang hanya menyimpan informasi secara horizontal, $Q R$ Code mampu menyimpan informasi secara horizontal dan vertikal, oleh karena itu secara otomatis $Q R$ Code dapat menampung informasi yang lebih banyak dari pada Barcode (Ching-yin, 2010).

$Q R$ Code juga dapat digunakan untuk menyimpan informasi-informasi lainnya seperti untuk menyimpan beberapa ID lain yang mungkin saja masih digunakan bersama-sama (Ridwan \& Haryo, 2010).

Pada sistem yang dirancang, penggunaan $Q R$ Code membantu untuk menyimpan data berupa hyperlink dengan parameter GET sebagai data yang akan di entry ke dalam database PMB. Contoh hyperlink yang tersimpan setelah dilakukan urlencode pada sistem generator $Q R$ Code :

http://192.168.1.1/?nama=Hendra\%20Gunawan\&kat $=I P A \& p i l 1=351 \&$ pil2 $=331 \& j e n k e l=L \& n o \_h p=0812$ 3456789\&mail=hendra\%40eng.uir.ac.id\&tgl_lahir=1 9951203.
Tabel 1 dibawah ini menjelaskan isi dari hyperlink untuk setiap variabel $G E T$ yang dikirimkan ke server PMB. Untuk hasil generate $Q R$ Code dari hyperlink diatas, dapat dilihat dari gambar 1.

Tabel 1. Konten Hyperlink

\begin{tabular}{|l|l|l|}
\hline No & \multicolumn{1}{|c|}{ Konten Hyperlink } & \multicolumn{1}{c|}{ Keterangan } \\
\hline 1. & http://192.168.1.1/ & IP Address Server \\
\hline 2. & nama=Hendra\%20Gunawan & nama dari Calon Mahasiswa \\
\hline 3. & kat=IPA & Kategori=IPA atau IPS \\
\hline 4. & pil1=351 & kode jurusan pilihan 1 \\
\hline 5. & Pil2=331 & kode jurusan pilihan 2 \\
\hline 6. & jenkel=L & jenis kelamin= L atau P \\
\hline 7. & no_hp=08123456789 & no handphone \\
\hline 8. & mail=hendra\%40eng.uir.ac.id & email calon mahasiswa \\
\hline 9. & tgl_lahir=19951203 & $\begin{array}{l}\text { tanggal lahir format } \\
\text { yyyymmdd }\end{array}$ \\
\hline
\end{tabular}

Keterangan singkat dari tabel diatas sebagai berikut, pada IP Address 192.168.1.1 merupakan destinasi dari data yang diletakan. Data tersebut menyangkut data nama calon mahasiswa, jurusan sekolah mengah atas, pilihan jurusan yang diinginkan pada Universitas dan diberikan 2 opsi penjurusan, jenis kelamin, nomor handphone dari calon mahasiswa yang digunakan nanti saat pengiriman kode login jika dinyatakan lulus, email, dan tanggal lahir dari calon mahasiswa.

Pembuatan atau pencetakan form $Q R$ Code dilakukan oleh calon mahasiswa melalui Web PMB

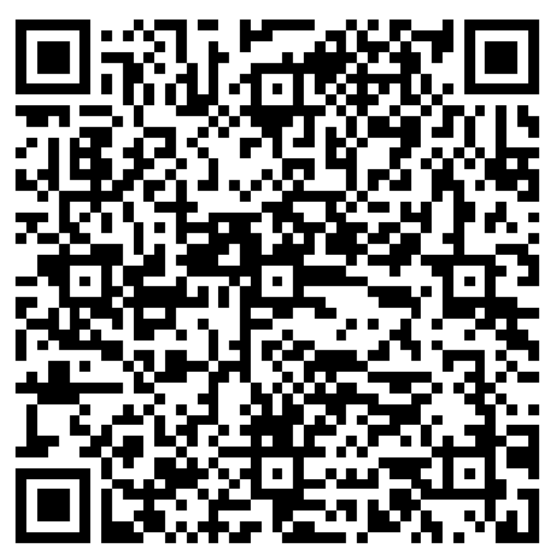

Gambar 1. Hasil generate QR Code dari hyperlink

secara online, hanya saja entry data tidak langsung masuk ke dalam database, tetapi hanya generate dalam bentuk $Q R$ Code. Hal ini dapat mengurangi resiko spam yang dilakukan oleh user yang menggunakan Web PMB. Kemudian setelah calon mahasiswa mencetak form $Q R$ Code, kemudian 
menyerahkan kepada panitia PMB untuk dilakukan scanning.

Setelah dilakukan scan $Q R$ Code oleh panitia $\mathrm{PMB}$, data tersebut secara otomatis tersimpan pada database PMB, kemudian setelah calon mahasiswa dinyatakan lulus, maka data tersebut wajib dilengkapi mahasiswa kembali secara online dengan menggunakan kode yang dikirimkan melalui pesan untuk digunakan sebagai kode login ke sistem.

\section{Analisa sistem yang berjalan}

Seleksi penerimaan mahasiswa baru atau disebut dengan SPMB di Universitas Islam Riau yang saat ini sedang berjalan, masih menggunakan sistem manual dimana pemanfaatan komputer hanya sebatas entry data mahasiswa bersangkutan apabila nanti mahasiswa tersebut telah dinyatakan lulus masuk Universitas.

Proses dimulai dengan calon mahasiswa datang ke Universitas dan membayar uang pendaftaran di Bank untuk langsung mendapatkan formulir pendaftaran masuk Universitas. Setelah itu calon mahasiswa mengisi formulir yang telah diberikan dan memberikan kepada panitia PMB dengan menyertakan fotocopy dokumen seperti ijazah atau pun STTB (Surat Tanda Tamat Belajar) dalam satu map dokumen.

Kemudian setelah calon mahasiswa memberikan persyaratan dan juga formulir pendaftaran kepada panitia PMB, panitia akan memberikan kartu ujian kepada calon mahasiswa beserta informasi mengenai tempat ujian bagi peserta ujian atau calon mahasiswa.

Calon mahasiswa atau peserta ujian PMB Universitas Islam Riau hanya tinggal menunggu waktu dilaksankanya ujian, dimana seluruh calon mahasiswa diseleksi secara bersamaan dengan tes tertulis. Untuk mengetahui pengumuman hasil seleksi, pihak Universitas akan mengumumkanya melaui media cetak, atau pun website Universitas pada waktu yang telah ditentukan.

Jika mahasiswa dinyatakan lulus dalam seleksi masuk Universitas yang diumumkan melalui media cetak maupun website Universitas, maka mahasiswa akan mendapatkan bukti kelulusan dari Biro Administrasi Akademik (BAA) Universitas yang dapat diambil di gedung Rektorat, ini merupakan proses terakhir dari alur Seleksi Penerimaan Mahasiswa Baru atau biasa disebut dengan SPMB dan setelah itu mahasiswa akan memenuhi kewajibanya seperti membayar uang masuk, pengambilan KRS, dan pendaftaran HER mahasiswa.

\section{Analisa sistem baru}

Melihat sistem yang sedang berjalan dilakukan secara manual dan dapat menimbulkan kesalahan entry data calon mahasiswa oleh panitia PMB, maka penulis membuat analisa sistem yang baru hendaknya dapat meningkatkan efisiensi pendaftaran baik dari sisi calon mahasiswa maupun panitia PMB UIR. Alur sistem baru dapat dilihat pada gambar 2 .

Pada gambar 2, terlihat calon mahasiswa harus mendaftarkan diri melalui Sistem PMB UIR secara online untuk mendapatkan $Q R$ Code dan di print untuk kemudian diserahkan kepada panitia PMB. Pada saat calon mahasiswa mengisi data diri pada Sistem PMB, sistem tidak memasukkan data di dalam database, tetapi hanya sebatas generate $Q R$ Code, hal ini dapat mencegah spam data pendaftaran.

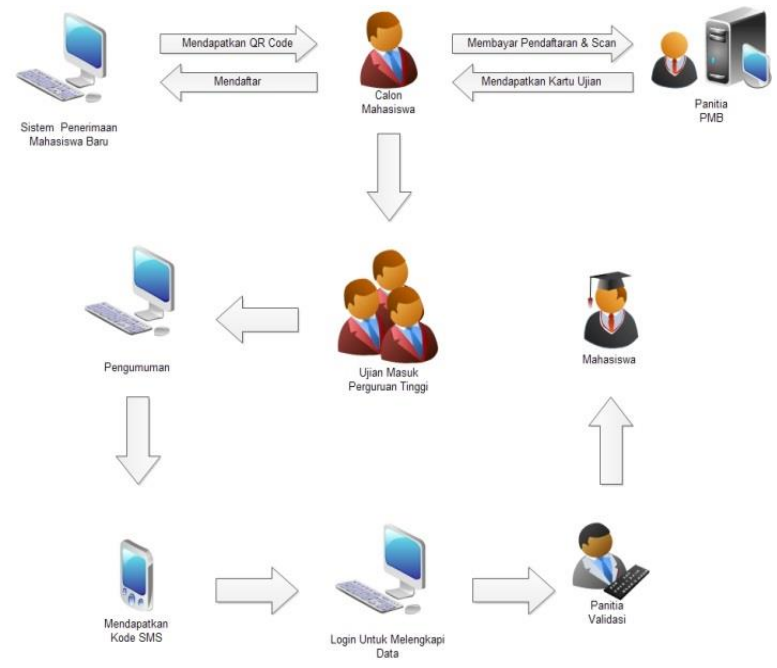

Gambar 2. Proses sistem PMB yang dirancang

Setelah lembaran $Q R$ Code di print oleh calon mahasiswa, maka calon mahasiswa dapat menyerahkan lembaran data diri yang disertai $Q R$ Code dan membayar biaya pendaftaran, agar dapat di scan oleh panitia dan data langsung masuk ke dalam database secara otomatis dengan menggunakan $U R L$ atau IP Address local pada komputer panitia. Sistem ini juga akan membantu panitia untuk mencetak kartu ujian setelah data masuk ke dalam database pada sistem baru.

Kemudian calon mahasiswa akan mengikuti ujian masuk perguruan tinggi dengan jadwal yang telah ditentukan. Pengumuman kelulusan akan ditampilkan pada website universitas, dan setiap calon mahasiswa yang dinyatakan lulus akan mendapatkan pesan singkat dengan menggunakan SMS Gateway yang 
berisi kode untuk melakukan login ke sistem PMB dan kemudian melengkapi data diri.

Seiring dengan perkembangannya, SMS tidak hanya dipergunkan untuk mengirmkan atau bertukar informasi antara dua orang yang saling mengenal atau membutuhkan, SMS juga sudah mulai dipergunakan untuk berhubungan antara seseorang dengan sebuah system sesuai dengan kebutuhan (Dewanto, 2007).

SMS Gateway ini menjadi alat bantu untuk melakukan pelayanan proses pendaftaran mahasiswa dengan cepat dan mudah melalui SMS, sehingga sumber daya yang ada dapat dimanfaatkan dengan efisien (Siagian \& Fernando, 2014).

Setelah data diri dilengkapi, maka calon mahasiswa harus menyerahkan fotocopy dokumen yang diperlukan seperti ijazah maupun STTB kepada panitia validasi sekaligus menunjukan dokumen asli. Proses penerimaan berkahir dan berlanjut ke proses melaksanakan kewajiban mahasiswa seperti pembayaran uang kuliah dan sebagainya.

\section{Perancangan Sistem}

\section{Contex Diagram}

Pada perancangan sistem ini, maka model data flow diagram dapat membantu untuk menggambarkan sistem, seperti yang terlihat pada gambar 3 context diagram sistem PMB.

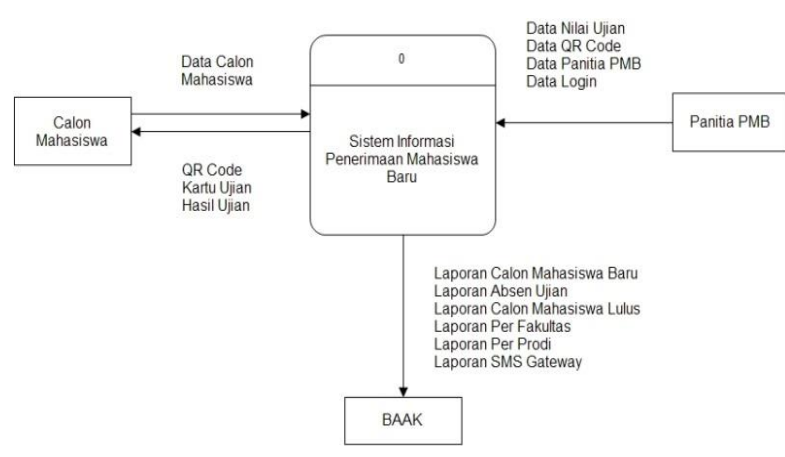

Gambar 3. Context Diagram Sistem PMB

verifikasi data calon mahasiswa baru. Setelah data yang ada pada $Q R$ Code discanning lalu data tersebut disimpan pada database yang sudah disiapkan dan mencetak kartu ujian bagi setiap calon mahasiswa baru untuk kartu tanda peserta seleksi.

\section{Rancangan Database}

Pada Sistem yang dibangun, dibutuhkan database PMB yang mempunyai beberapa tabel utama, diantaranya: Tabel Fakultas, Tabel Prodi dan Tabel
Calon Mahasiswa. Informasi field pada setiap tabel dapat dilihat dilihat pada tabel 2, 3, dan 4 berikut :

Tabel 2. Tabel Fakultas

\begin{tabular}{|l|l|l|l|}
\hline No & \multicolumn{1}{|c|}{ Field Name } & Data Type & Field size \\
\hline 1 & Kode_fakultas $(*)$ & Char & 2 \\
\hline 2 & Nama_fakultas & Varchar & 25 \\
\hline
\end{tabular}

Tabel 2 diatas adalah struktur data yang berisi data mengenai Fakultas-Fakultas yang berada di Universitas Islam Riau. Field Kode_fakultas merupakan field untuk kode masing-masing fakultas, field ini merupakan primary key untuk tabel Fakultas dimana kode untuk masing-masing Fakultas merupakan kode unik yang berbeda satu sama lain. Field Nama_fakultas adalah nama untuk masing-masing Fakultas yang ada di Universitas Islam Riau.

Tabel 3. Tabel Prodi

\begin{tabular}{|l|l|l|l|}
\hline No & Field Name & Data Type & Field size \\
\hline 1 & Kode_prodi $(*)$ & Char & 3 \\
\hline 2 & Nama_prodi & Varchar & 50 \\
\hline 3 & Jenjang & Varchar & 3 \\
\hline 4 & Kelompok & Char & 2 \\
\hline 5 & Kode_fakultas & Char & 2 \\
\hline
\end{tabular}

Tabel 3 merupakan struktur tabel yang berisi data jurusan yang berada di Universitas Islam Riau. Dimulai dari Kode_prodi yang merupakan primary key dari Tabel Prodi. Kemudian ada field Nama_prodi untuk nama prodi yang diatur menampung 50 karakter nama prodi. Field jenjang adalah jenjang pendidikan yang disediakan oleh prodi untuk mahasiswa baik itu diploma, sarjana, maupun pascasarjana. Kemudian ada Foreign Key Fakultas yang diambil dari tabel data Fakultas yang digunakan sebagai key untuk Fakultas dimana prodi berada pada tabel Prodi.

Tabel 4. Tabel Calon Mahasiswa

\begin{tabular}{|l|l|l|l|}
\hline No & \multicolumn{1}{|c|}{ Field Name } & Data Type & Field size \\
\hline 1 & No_test $(*)$ & Char & 15 \\
\hline 2 & Nama & Varchar & 30 \\
\hline 3 & Tempat_lahir & Varhcar & 25 \\
\hline 4 & Tanggal_lahir & Date & \\
\hline 5 & Alamat & Varchar & 50 \\
\hline 6 & Jenis_kelamin & Varchar & 2 \\
\hline 7 & No_hp & Varchar & 12 \\
\hline 8 & Email & Varchar & 30 \\
\hline 9 & Agama & Varchar & 8 \\
\hline
\end{tabular}




\begin{tabular}{|l|l|l|l|}
\hline 10 & Pilihan1 & Varchar & 3 \\
\hline 11 & Pilihan 2 & Varchar & 3 \\
\hline 12 & No_Ijazah & Varchar & 15 \\
\hline 13 & Tanggal_Ijazah & Date & \\
\hline 14 & Jenis_Sekolah & Varchar & 4 \\
\hline 15 & Nama_sekolah & Varchar & 20 \\
\hline 16 & Alamat_sekolah & Varchar & 50 \\
\hline 17 & Kotamadya_sekolah & Varchar & 25 \\
\hline 18 & Propinsi_sekolah & Varchar & 25 \\
\hline 19 & Nilai_UN & Float & \\
\hline 20 & Nama_Ayah & Varchar & 50 \\
\hline 21 & Nama_Ibu & Varchar & 50 \\
\hline 22 & Pekerjaan_orangtua & Varchar & 2 \\
\hline 23 & Alamat_orangtua & Varchar & 50 \\
\hline 24 & Hp_Ortu & Varchar & 12 \\
\hline 25 & Pendidikan_Ayah & Varchar & 2 \\
\hline 26 & Pendidikan_Ibu & Varchar & 2 \\
\hline 27 & Nilai_Ujian & Int & 3 \\
\hline
\end{tabular}

Tabel 4 merupakan struktur data dari database calon mahasiswa dimana informasi lengkap mengenai calon mahasiswa harus diisi. Field No_test merupakan

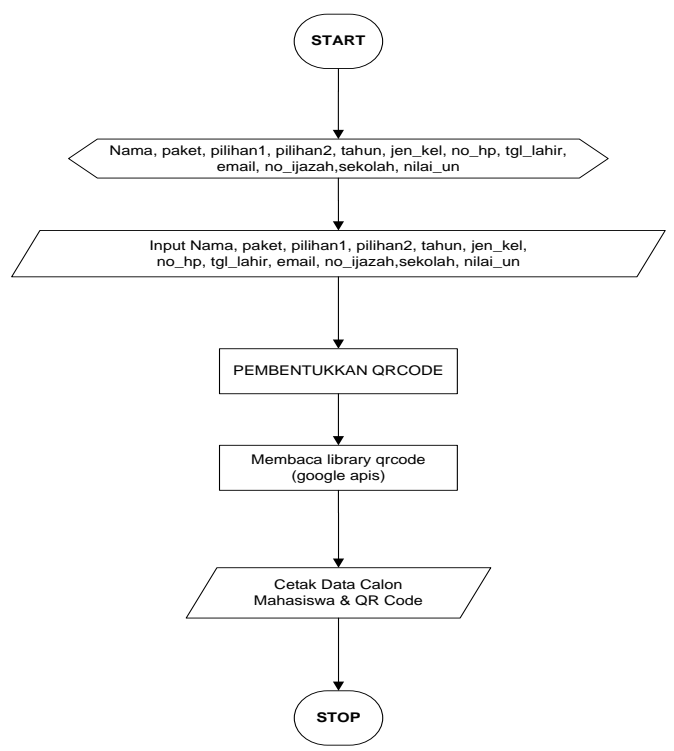

Gambar 4. Flowchart generate QR Code

primary key pada tabel 4 dimana nomor tes calon mahasiswa merupakan nomor unik yang juga menjadi kata kunci pada database.

\section{Flow Chart Sistem}

Rancangan Flowchart pada sistem yang dibuat ada 3, yaitu : a. Flowchart generate QR Code.

Flowchart ini menerangkan proses logika untuk data yang di entri oleh calon mahasiswa menjadi bentuk gambar $Q R$ Code dengan memanfaatkan library atau API generator QR Code.

b. Flowchart pembuatan nomor tes.

Flowchart ini menerangkan proses membangkitkan no tes setiap calon mahasiswa baru yang dikelompokkan menurut prodi pada pilihan 1 .

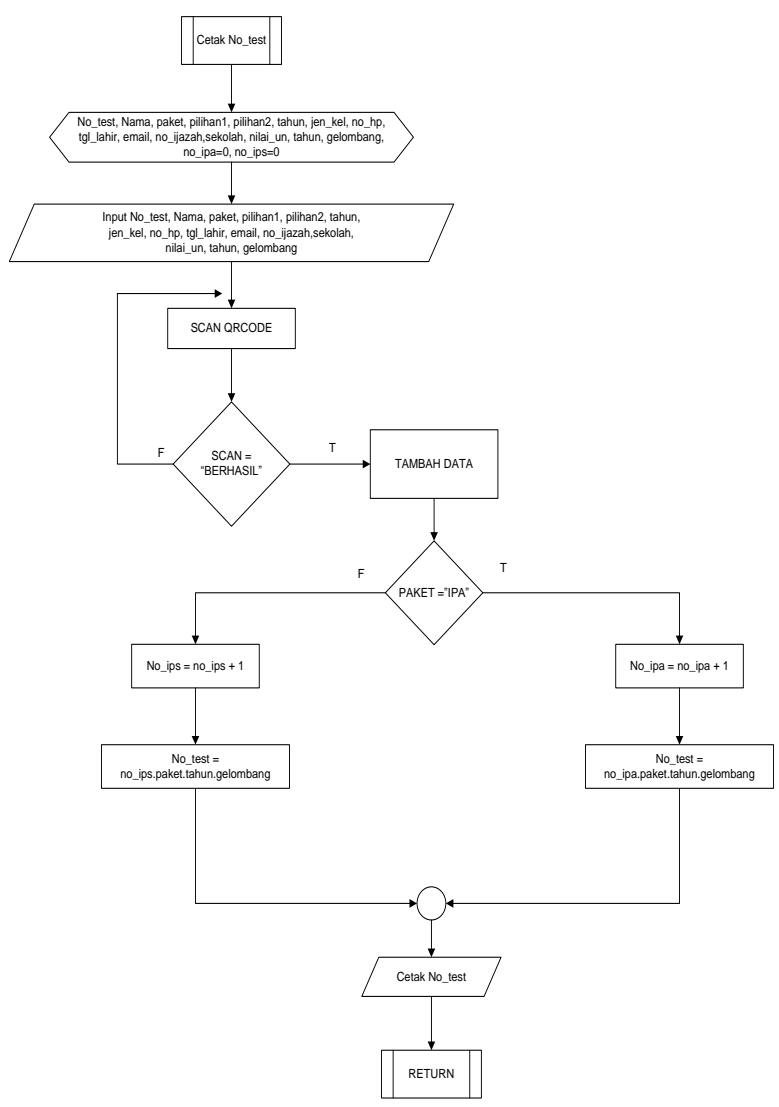

Gambar 5. Flowchart pembuatan nomor tes Calon Mahasiswa Baru

Pada gambar 5 diatas, flowchart menggambarkan bagaimana sistem membuat nomor tes calon mahasiswa berdasarkan paket yang diambil oleh calon mahasiswa tersebut. 
c. Flowchart cetak kartu ujian.

Flowchart ini menerangkan proses pencetakan kartu ujian yang dilakukan oleh panitia PMB.

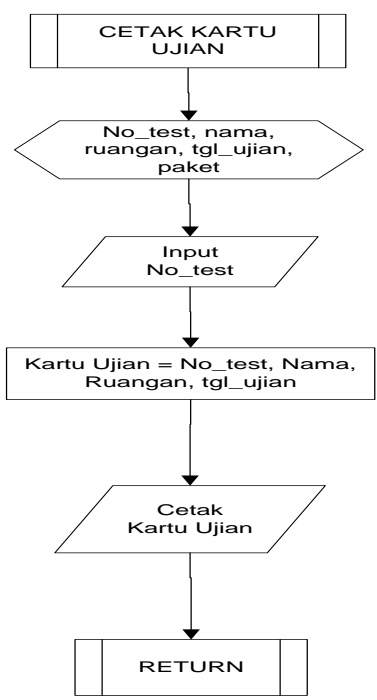

\section{Gambar 6. Flowchart Cetak kartu ujian}

Mencetak kartu ujian bagi calon mahasiswa yang mendaftar dilakukan oleh panitian PMB sesaat setelah calon mahasiswa melakukan scanning $Q R$ Code dan mendapatkan nomor ujian.

\section{HASIL DAN PEMBAHASAN}

\section{Pengujian Form Generate $Q R$ Code}

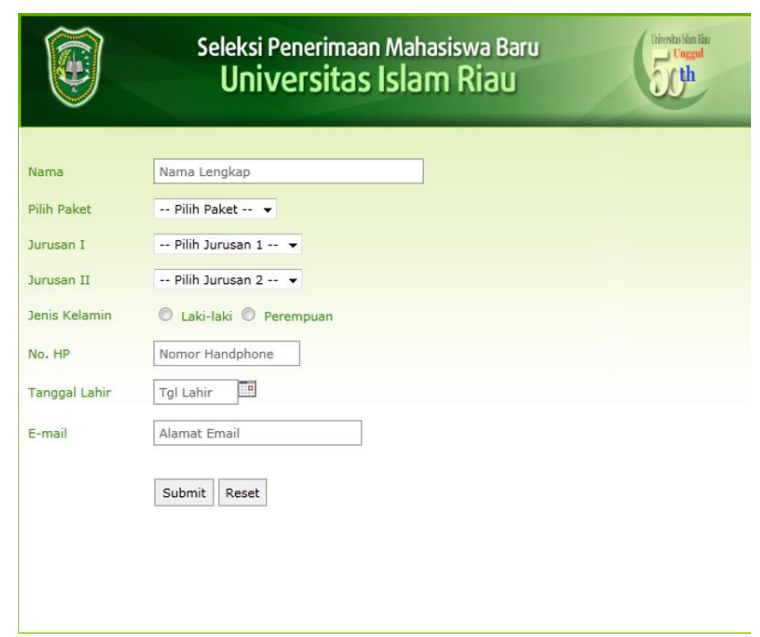

Gambar 7. Form online generate QR Code
Tampilan pembuatan $Q R$ Code setiap calon mahasiswa baru. Form yang terlihat pada gambar 7 merupakan form online dimana calon mahasiswa dapat membuat $Q R$ Code serta mencetaknya dari file $P D F$ yang di generate sistem.

Dapat dilihat dari hasil sistem yang dibuat dengan menggunakan $Q R$ Code efisiensi yang didapatkan telah sesuai dengan harapan. Dimana penggunaan $Q R$ Code bagi mahasiswa yang mendaftar dapat menghemat database yang tersedia untuk sistem Penerimaan Mahasiswa Baru (PMB).

Field yang diberikan hanya sebatas informasi singkat calon mahasiswa, karena nantinya pelengkapan data calon mahasiswa akan dilaksanakan jika calon mahasiswa telah ditetapkan menjadi mahasiswa Universitas Islam Riau.

Dan jika dibandingkan sistem lama yang dipakai oleh Universitas Islam Riau dengan sistem baru yang saat ini sedang diteliti dan diujicobakan maka ada perubahan dominan yang terjadi. Mulai dari awal proses pendaftaran hingga calon mahasiswa dinyatakan lulus menjadi seorang mahasiswa.

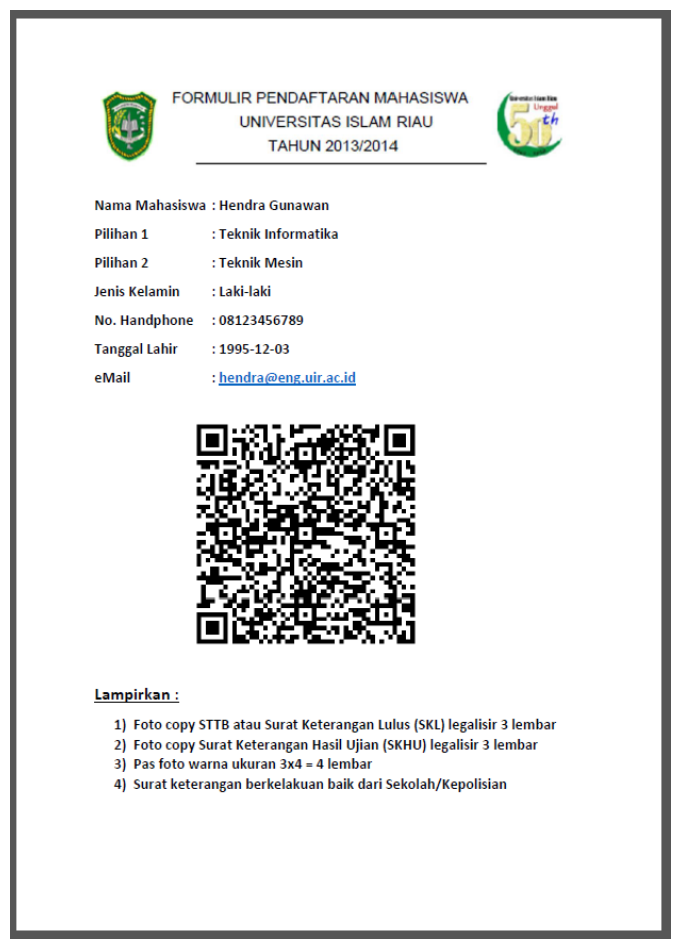

Gambar 8. Hasil print QR Code dalam format PDF 
Pada gambar 8, merupakan hasil dari print data $P D F$ berisi data diri calon mahasiswa beserta $Q R$ Code. Hasil dari print tersebut harus diserahkan kepada panitia PMB sekaligus membayar biaya pendaftaran.

\section{Pengujian Scan Gambar QR Code}

Untuk pengujian scan $Q R$ Code dilakukan dengan alat scan yaitu Smartphone Android Samsung Ace dan aplikasi yang digunakan adalah $Q R$ Droid.

Pada dasarnya untuk pengujian scan $Q R$ Code dapat dilakukan dengan berbagai macam tipe handset lainnya, dan begitu pula dengan software scanning tidak harus menggunakan $Q R$ Droid, namun penguji berpendapat bahwa proses yang berlangsung tidak boleh terpengaruhi oleh handset maupun software yang digunakan sehingga selama hal tersebut tidak berubah maka diperbolehkan menggunakan perangkat lain.

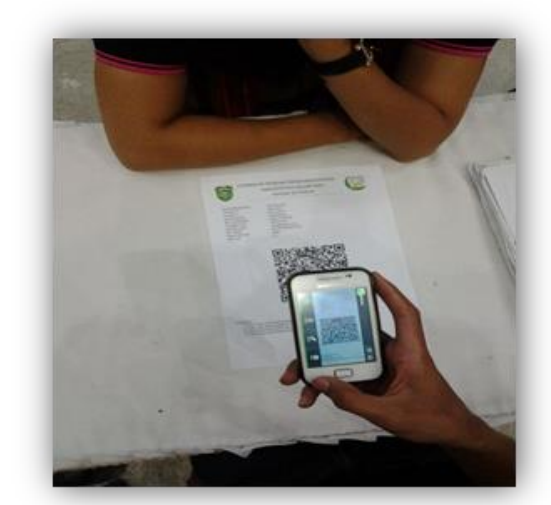

\section{Gambar 9. Scan QR Code Calon Mahasiswa Baru}

Setelah gambar $Q R$ Code yang ada pada formulir di scan maka akan masuk kedalam database, sehingga data calon mahasiswa dapat diolah sesuai dengan kebutuhan. Saat data masuk ke dalam database PMB, sistem dengan otomatis membuat no tes calon mahasiswa tersebut.

\section{IV.KESIMPULAN}

Dari hasil pengujian yang sudah dilakukan dapat diambil kesimpulan sebagai berikut :

1. Form pengisian data online untuk membuat $Q R$ Code dapat membantu calon mahasiswa untuk mencetak $Q R$ Code pendaftaran.

2. Tidak terjadinya spam atau data sampah pada pendaftaran online, data yang masuk pendaftaran harus melewati scan panitia PMB, sekaligus membayar biaya pendaftaran.
3. Form online lebih cepat jika diakses secara bersamaan oleh banyak calon mahasiswa sekaligus, karena sistem online tidak langsung menyimpan kedalam database.

4. Minimnya tingkat kemungkinan data di hack atau dicuri secara online, karena server PMB hanya diakses melalui jaringan LAN kampus UIR.

\section{DAFTAR PUSTAKA}

[1] Siagian, Pandapotan., Fernando, Erick., "Sistem Informasi Penerimaan Mahasiswa Baru dengan SMS gateway". Jurnal Sistem Informasi (JSI), Vol 6, No 1, April 2014.

[2] Law, Ching-yin. "QR Codes in Education", Journal of Educational Technology Development and Exchange, 2010.

[3] Ridwan, Fridh Zurriyadi, Santoso, Hariyo, Agung, dan Wiseto P, "Mengamankan Single Identity Number (SIN) Menggunakan Qrcode dan Sidik Jari”, 2010.

[4] RA, Dewanto dan Aradea. (2011, Oktober 25) Aplikasi SMS Gateway dengan Koreksi Kesalahan Menggunakan Fuzzy String Matching [online].Available:http://journal.uii.ac.id/index.p hp/Snati/article/viewFile/1642/1417. 